\title{
Measuring on Farm Diversity and Determinants of Barley Diversity in Tigray, Northern Ethiopia
}

\author{
Fetien Abay ${ }^{1 *}$ Asmund Bjørnstad ${ }^{2}$ and Melinda Smale $^{3}$ \\ ${ }^{1 *}$ Department of Dry land Crop and Horticultural Sciences, P.O. Box 231, Mekelle University, \\ Mekelle, Ethiopia (fetien.abay@yahoo.com) \\ 2 Department of Plant and Environmental Sciences, Norwegian University of Life Sciences, \\ P.O. Box 5003, N-1432 Aas, Norway \\ ${ }^{3}$ International Food Policy Research Institute 2033 K Street, NW, Washington, DC 20006-1002, \\ USA
}

\begin{abstract}
Maintaining on-farm diversity of crop varieties has received increasing attention as a strategy for mitigating production risk and protecting food security in resource-poor farming systems with few opportunities for insurance or trade. Barley is grown under a wide range of environmental conditions and in marginal areas or seasons where the production of other cereals is limited. Food consumption preferences and variable tolerance to biotic and abiotic stresses influence the mixture and number of varieties to be grown. Phenotypic diversity was determined using Shannon diversity index. An econometric approach has been applied to identify the social and economic factors that influence levels of diversity maintained on-farm.

A high phenotypic diversity index (0.79) was recorded from sampled barley varieties. Censored regression indicates that physical characteristics of the farm (land fragmentation index, farm size), agro climatic features of the site (altitude, rainfall, temperature) and household characteristics (only number of children) had a significant and positive impact on diversity and area allocation of barley. The significant negative relation of number of extension contact with barley diversity implies further attention and analysis.
\end{abstract}

Key words: On farm diversity, Determinants of diversity, On farm conservation, Diversity index

\section{INTRODUCTION}

Maintaining on-farm diversity of crop varieties has received increasing attention as a strategy for mitigating production risk and protecting food security in resource farming systems with few opportunities for insurance or trade. For poorer farmers on marginal lands, crop variety diversification increases options for coping with variable environmental conditions and exploiting niches and microenvironments within agro-ecosystems. The highlands of Ethiopia are known internationally to harbor valuable barley genetic resources. Previous studies have documented considerable variation in morphology, maturity, high lysine (Munck et al., 1971), disease reaction (Qualset 1975; Van Leur and Hailu, 2003), and frost tolerance (Reinheimer, 2004), high water-use efficiency, tolerance to nitrogen and water stresses (G'orny, 2001). 
However, such traits, and particularly the abiotic stresses (frost tolerance, water-use efficiency and drought stress), have not yet been fully exploited.

The objectives of this study are to: (1) examine the agro-morphological diversity of barley varieties; (2) assess the social and economic determinants of barley diversity on farms in Tigray, northern Ethiopia; and (3) understand whether farmers themselves promote diversity through evaluating their preferences. This study uses a holistic analysis that pools social, economic, and adaptive, agro-morphological analysis.

A study on the current status of barley diversity and its determinants is useful as input to policy decisions concerning conservation and improvement of farmer livelihoods. As a first step, it is important to know if farmers promote diversity and how they value it. If they do, the public costs of supporting the maintenance of barley diversity will be lower. Since barley is important for the poor in marginal areas and its production in Tigray depends entirely on farmers' varieties, Tigray is an ideal site for studying dynamics of local barley diversity in low-external-input farming systems. For breeding and conservation policies in Ethiopia, it is important to identify trade-offs in farmer decision-making, such as variety choices that are positive from the standpoint of livelihoods, but that affect genetic diversity negatively by favoring certain crops or genotypes, management practices or particular micro-environments.

\section{BACKGROUND TO THE STUDY}

The Tigray region in northern Ethiopia is generally regarded as the most environmentally degraded part of the country. Rainfall is erratic and insufficient, and soils are generally poor. The complex, environmental stresses faced by farmers are exacerbated by low availability of infrastructure (inputs, markets). In order to cope, farmers have depended on a wide range of diversity of species and varieties to address their needs. Barley, a major crop in the region, is grown under a wide range of environmental conditions, in marginal areas, or during seasons when the production of other cereals is limited. At regional level barley ranked $6^{\text {th }}$ in terms of share from total production, where as in terms of share from total areas sown, it ranked $3^{\text {rd }}$ behind sorghum (Sorghum bicolor) and Tef (Eragrostis tef) (BoARD, 2005). It is grown in main and shorter seasons: "Meher" (June-December) is the main growing season and "Belg" (February-May) is the shorter season. Off season (residual moisture) cropping is also practiced for barley in the central and eastern part of the region. 
In the study region the use of external inputs is minimal and no "improved" (i.e. introduced) variety of barley adopted by farmers. This has led farmers to rely on their own varieties for seed management and on their own production. The popularity of barley can be associated with the consumption habits of the people, which accounts for over $60 \%$ of the food for the inhabitants of Ethiopian highlands (Maaza and Lakech, 1996). Farmer's decisions on where to plant may affect crop diversity in several ways. Choosing a particular site will expose the population to natural selection processes that may result in selection for tolerance to a particular stress related to that microenvironment. Almekinders et al. (1994) describe the use of local varieties for variable environments, saying that farmers use genetic variation in crops to match variation in soil conditions between and within fields. They illustrate this with a case study of Mende rice farmers in Sierra Leone. The value of local varieties as a source of drought resistance was shown by Grando et al. (2001). Teshome et al. (1997, 1999) showed that sorghum landrace diversity in Ethiopia was significantly related to a number of farmer selection criteria. Bellon and Taylor (1993) look into the link between folk soil taxonomy (i.e. perceived agro ecological conditions) and uptake of new varieties. The strong exchange of seeds with farmers within and along their neighbor villages has shown their multiple criteria for yield stability (Ellis, 1993), straw production (Haugerud and Collinson, 1990), feed value (Ceccarelli et al., 1996) or soil fertility (Bellon and Taylor, 1993). The multiple traits that came out of these objectives are the major factors in varietial diversity of their fields (Teshome et al., 1997; Brush and Meng, 1998). In addition to these factors, farmers have not discarded material when conditions are uncertain.

Over the past decade, the area planted to barley has declined by $31 \%$. The ratio of area grown today as compared to 13 years ago is $69 \%, 114 \%$ and $160 \%$ for barley, wheat and Hanfetz, mixed cropping of barley and wheat, respectively. Hanfetz has been introduced by farmers mainly to address the abiotic (water logging) and biotic (diseases and insects) stresses of both wheat and barley crops. It is preferred for its yield stability than respective sole cropping (Araya and Stuck, 2005), though known to replace either of the crops or both.

Average grain yield of barley in the region ( $t / h a)$ is also low compared to the national average (0.99 t/ha), which ranges from 0.6 to 2.0 t/ha (Birhanu et al., 2005). In addition to its sensitivity to water logging problems, one contributor to the reduction in barley area and productivity could be the low priority given to barley in agricultural development, conservation and research programs, as compared to the emphasis placed on higher-valued export crops. Agricultural 
extension policy in Tigray region has focused on wheat (mainly for bakeries), pulses and horticultural crops, and has given little attention to the crops and crop products grown by poor farmers who sell on local rural and urban markets.

Despite farmers' efforts (Abay et al., 2008) and researchers' understanding of the critical importance of barley for drought-prone areas (Birhanu et al., 2005), the diversity of barley in Tigray has not been documented although geneticists have mentioned it anecdotally (Demissie and Bjørnstad, 1997) in some instances, and samples studied did not include major production regions like Tigray. The economic determinants of cereal diversity have been described in general, with no detail study on barley (Benin et al., 2004) and the influence of family size and number of contacts with extension agents has not been considered in their study. Furthermore, the studies made by economists and geneticists made separately and the ethno botanical linkage of barley diversity to farmer livelihoods were not addressed.

The study comprises two sections. The first section provides an agro-morphological characterization of barley collected from the Tigray region, using Shannon diversity index. This section reveals the current status of barley diversity on farms in Tigray. The second section identifies the economic factors that influence barley diversity levels, using a multivariate analysis and a MDPR (Multidimensional Preference) analysis and finally, implications and conclusions are presented.

\section{MATERIALS AND METHODS}

\subsection{Genetic materials}

A sample of ten distinctly named farmers' varieties was drawn from farmers' fields in the study sites, late in the season before harvest, when the plants were still in the field (Table 1). Forty lines extracted from two accessions of the Tigray collection of the Institute of Biodiversity Conservation (IBC) were procured from a previous study of Ethiopian barley collections (Demissie and Bjørnstad, 1996). In the first year, a total of 240 pure lines were extracted, and planted at Sheno (North Shewa) and Mekele (Tigray) sites. In the second year, the experiment was laid in augmented design, using $0.2 \mathrm{~m}$ and $0.4 \mathrm{~m}$ to separate rows and plots (lines), respectively. A standard improved check and popular local varieties were used at Sheno and Mekele sites, respectively. The checks were augmented and randomized throughout the blocks. Data were recorded from triplet rows of plots of $1.5 \mathrm{~m}^{2}$, each representing a line. Five plants 
were randomly selected and labeled by string. Their average data were used for final analysis The agro morphological characters were then recorded according to various plant parts, seed, flower, and grain and spike characteristics including useful traits like growth habit and response to disease (IPGRI, 1994). Prior to statistical analysis, the quantitative traits were converted to discrete traits to avoid any discrepancy and reduce the error encountered in handling different measurement units of qualitative and quantitative data. A list of 17 traits used in the study is presented in Table 2. Each phenotypic range of the quantitative trait was divided into four classes. The range and proportion of different classes of quantitative and qualitative traits were calculated.

\subsection{Econometrics approach}

\subsubsection{Data source}

The multivariate analysis was preceded by Participatory Rural Appraisal (PRA) tools to understand the status of barley diversity in the villages. Direct field observations were made on barley fields, farming systems and management practices. Key informant interviews and Focus Group Discussions (FGDs) were conducted to document the knowledge and preference ranking of farmers. The survey design consisted of two stages. In the first stage, five study districts were selected using secondary data from BoARD (2005). The study sites were purposely selected in terms of area coverage for barley, constraining levels of drought, varying agro-ecology and consumption preferences. The location of the study sites is shown in Fig.1. In the second stage, one village was randomly selected from each district, except Gantafeshum where two districts were chosen. Additional village was considered for this district because of the higher importance of barley in terms of area coverage and cultural values (BOARD, 2005). At the beginning, 100 households were randomly sampled from the list of households. An initial survey was made to the households in order to identify barley growing farmers. Finally, 50 barley growers were drawn from each site. Of 300 surveyed, 249 were complete for data analysis. The variables used were constructed from data collected in a sample survey of seven villages in the six districts 


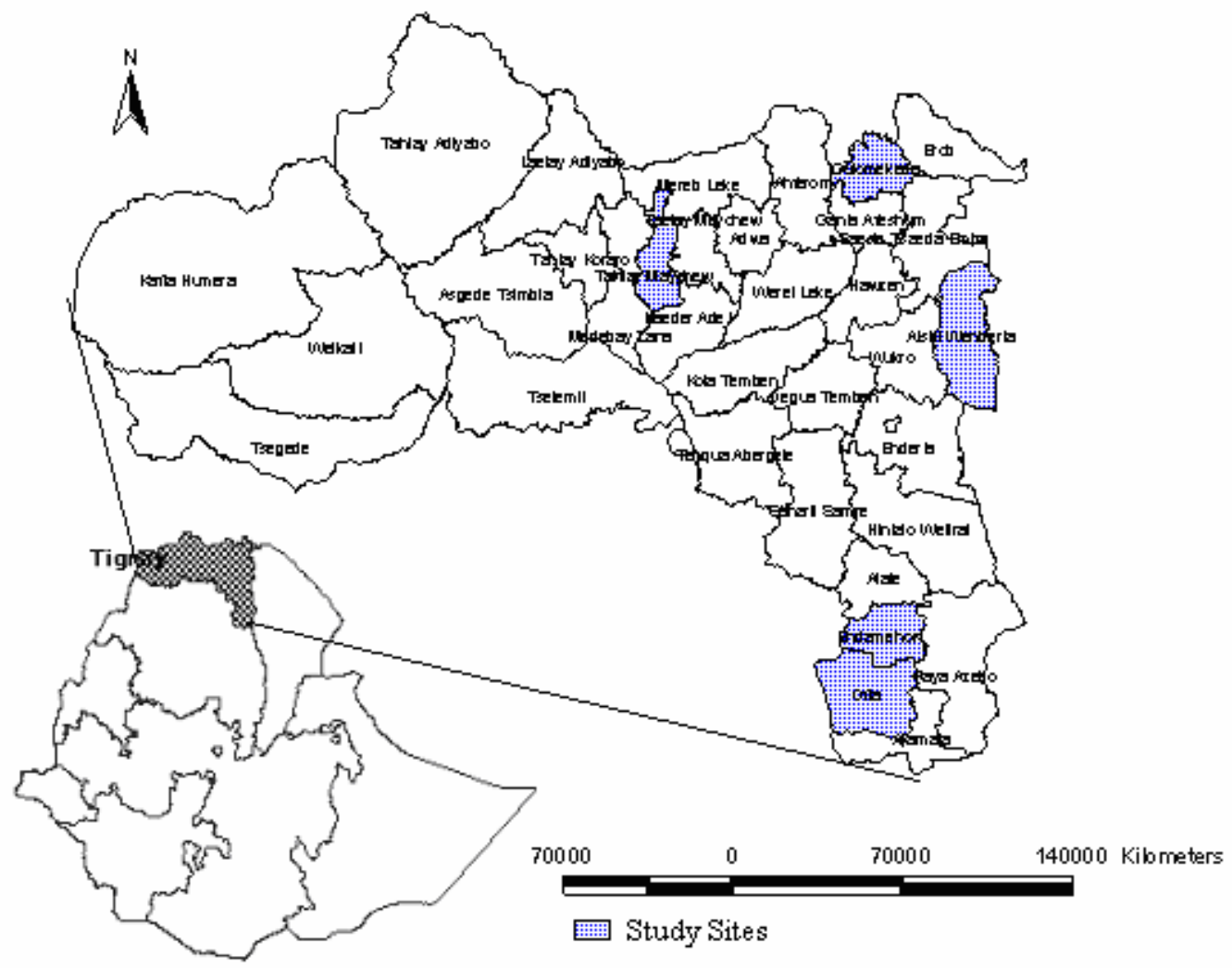

Figure 1. Map of Ethiopia and study sites in Tigray.

Table 1. List of Source Varieties for Pure Line Extraction by Row Type, Maturity, Collection District and status.

\begin{tabular}{|c|c|c|c|c|c|}
\hline $\begin{array}{l}\text { Variety/ } \\
\text { AccNo }\end{array}$ & $\begin{array}{l}\text { Row } \\
\text { Number }\end{array}$ & Maturity & Collection district & $\begin{array}{l}\text { HH } \\
\text { share } \\
(\%)\end{array}$ & Status $^{\text {**k }}$ \\
\hline Gunaza & Six & Late & Atsbi-Wemberta & 6.5 & $\begin{array}{l}\text { Common in different } \\
\text { areas }\end{array}$ \\
\hline Kintsbe & Two & early & Atsbi-Wemberta & 9.1 & Popular in the area \\
\hline Burguda & Two & medium & Atsbi-Wemberta & 4.7 & Popular in the area \\
\hline Himblil & Six & Medium & Endamekhoni & 3.1 & $\begin{array}{l}\text { Popular and specific } \\
\text { to the area }\end{array}$ \\
\hline Shewa & Six & Late & Endamekhoni & 4.1 & $\begin{array}{l}\text { Popular and specific } \\
\text { to the area }\end{array}$ \\
\hline Zibna & Two & Early & Endamekhoni & 0.3 & Specific to the area \\
\hline Kinchiso & Six & late & Endamekhoni & 1.3 & Specific to the area \\
\hline Atsa & Two & medium & Ganta-Afeshum & 1.8 & Found in few sites \\
\hline Atona & Irregular & Late & Ganta-Afeshum & 1.8 & Found in few sites \\
\hline Saesa & Two & early & Tahtay-Maychew & & Popular across all sites \\
\hline 219910 (IBC1) & Six & Late & Adwa & & \\
\hline 2223185 (IBC2) & & Medium & Adishhu & & \\
\hline
\end{tabular}

According to the farmers perception based on the area coverage and proportion of households growing it. 
Table 2. Characters Examined and their Respective Classes.

\begin{tabular}{|c|c|c|c|c|c|c|c|}
\hline Trait* & Class & Code & $\begin{array}{l}\text { Range/ } \\
\text { Frequency }\end{array}$ & Trait* & Trait/State & Code & Frequency \\
\hline \multirow{4}{*}{ DAFL } & $\leq 50$ & 1 & & ROWNO & Two rowed & 1 & 40.2 \\
\hline & $\overline{5} 1-58$ & 2 & Mean 75 & & Irregular & 3 & 37.7 \\
\hline & $59-66$ & 3 & Min 47 & & Six rowed. & 5 & 22.2 \\
\hline & $\geq 67$ & 4 & Max. 93 & $\mathrm{RACH}$ & Short & 1 & 52.9 \\
\hline \multirow[t]{4}{*}{ DAM } & $\leq 97$ & 1 & Mean 121 & & Long & 2 & 47.1 \\
\hline & $98-115$ & 2 & Min 85 & & & & \\
\hline & $116-133$ & 3 & Max. 147 & LEMTP & $\begin{array}{l}\text { No lemma } \\
\text { teeth }\end{array}$ & 1 & 79.1 \\
\hline & $\geq 134$ & 4 & & & Lemma teeth & 2 & 18.8 \\
\hline \multirow[t]{4}{*}{$\mathrm{PH}$} & $\leq 45$ & 1 & Mean 49 & & Lemma hair & 3 & 2.1 \\
\hline & $46-66$ & 2 & $\begin{array}{l}\text { Min } 29 \\
\text { Max. } 87\end{array}$ & LEMCO & $\begin{array}{l}\text { Amber } \\
\text { (normal) }\end{array}$ & 1 & 76.9 \\
\hline & $67-87$ & 3 & & & Tan/red & 2 & 0 \\
\hline & $\geq 88$ & 4 & & & Purple & 3 & 0 \\
\hline \multirow[t]{4}{*}{ SEED/SPK } & $\leq 26$ & 1 & Mean 28 & & Black/grey & 4 & 23.1 \\
\hline & $27-48$ & 2 & Min 11 & SEEDCO & White & 1 & 71.5 \\
\hline & $49-70$ & 3 & Max. 67 & & Tan/red & 2 & 15.5 \\
\hline & $\geq 71$ & 4 & & & Purple & 3 & 0.4 \\
\hline \multirow[t]{4}{*}{ SPKLEN } & $\leq 5$ & 1 & Mean 5 & & Black & 4 & 12.6 \\
\hline & $6-8$ & 2 & Min 3 & GRHB & Prostrate & 3 & 2.5 \\
\hline & $9-11$ & 3 & Max. 10 & & Intermediate & 5 & 8.4 \\
\hline & $\geq 17$ & 4 & & & Erect & 7 & 89.1 \\
\hline \multirow[t]{4}{*}{ SCALD } & Resistant & 1 & 31.5 & ALCO & White & 1 & 81.2 \\
\hline & Moderate & 2 & 13.5 & & Blue & 2 & 18.8 \\
\hline & Susceptible & 3 & 18.5 & GLCO & White & 1 & 50.2 \\
\hline & $\begin{array}{l}\text { Very } \\
\text { Susceptible }\end{array}$ & 4 & 36.5 & & Yellow & 2 & 18.8 \\
\hline \multirow{3}{*}{ SPKD } & Lax & 3 & 10.9 & & Brown & 3 & 20.9 \\
\hline & Intermediate & 5 & 81.1 & & Black & 4 & 10.0 \\
\hline & Dense & 7 & 8.0 & AWNRUG & Smooth & 3 & 20.1 \\
\hline \multirow[t]{3}{*}{ KECO } & Naked & 1 & 8.8 & & Intermediate & 5 & 72.0 \\
\hline & Semi Covered & 2 & 0 & & Rough & 7 & 7.9 \\
\hline & Covered & 3 & 91.2 & & & & \\
\hline
\end{tabular}

*DAFL $=$ Days to Flowering, DAM=Days to Maturity, $\mathrm{PH}=$ Plant Height, SEED/SPK= Number of Seeds per Spike. SCALD = Scald Resistance SPKD $=$ Spike Density, KECO = Kernel Cover, ROWNO= Row Number, RACH= Rachila Hair Length, LEMTP= Lemma Type, LEMCO= Lemma Color, $\mathrm{SEEDCO}=$ Seed Color, $\mathrm{GRHB}=$ Growth Habit, $\mathrm{ALCO}=$ Alurone Color, $\mathrm{GLCO}=$ Glume Color, and AWNRUG $=$ Awn Roughness

\subsubsection{Dependent variables}

The three diversity indices used as dependent variables have been adapted from ecological indices of spatial diversity, as defined by Magurran (2004). The first is the Margalef index, typically calculated over large areas and samples. The numerator of the Margalef index is defined as the number of species or sub-species (local varieties in our case) less one. 


\section{$M=(L-1) / \ln C \quad M \geq 0$}

$\mathrm{L}$ refers to the number of local varieties, while $\mathrm{C}$ refers to total area allocated to each landraces. Evenness as measured by the Shannon-Weaver index was used. This index is defined as follows $\mathbf{H}=-\sum_{i}^{n} p_{i} \ln p_{i} \quad \mathbf{P i} \geq \mathbf{0}$

Where, pi is area share occupied by variety $i$. The relative abundance was measured by BergerParker- Index which measures the "distribution of individuals in a system among different species" (Berger and Parker, 1970).

It was calculated as:

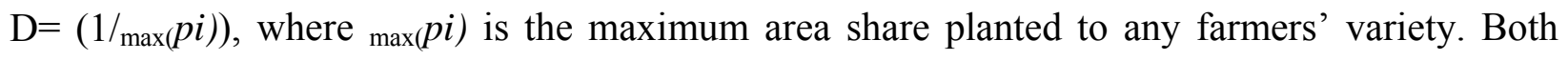
Margalef and Shannon have a lower limit of zero if only one variety is grown and the BergerParker index has a lower limit of one when a single variety occupies all of the area

\subsubsection{Independent Variables}

The independent variables are operational measurements representing household, farm and agroecological characteristics. Their hypothesized effects are as explained below. Variable 'age' and its squared term are considered to influence diversity in its linear and quadratic forms respectively; this might be because of time tested knowledge on barley and their higher preferences on barley products. Young farmers are expected to have the chance to be educated and exposed to new technology and less inclined to promote indigenous crops like barley. Women household heads are thought to influence diversity in positive and negative ways. It is expected that women's knowledge in seed selection and management would contribute towards increased richness. On the other hand, their low economic position, e.g. lack of ox and skill to plough may influence their decisions to grow less number of varieties. Households with large number of dependents are expected to grow more barley varieties and to grow barley in large area. Barley is the earliest cereal and grows with relatively low labor and input demand. Most of the highland areas are barley-based farming systems. Straw is a major feed source for large animals' (mainly cattle and oxen). This implies that higher numbers of large animals are associated with increased number of barley varieties. Years of formal schooling is hypothesized to influence diversity in either a positive or negative way. This is because of the increased level of awareness of educated farmers on the benefit of biodiversity but also their inclination towards new technology. 
The frequency of contact with extension agents is expected to enhance the farmer access to information that increases adoption of introduced varieties. There is no particular focus on dissemination of barley varieties because there is no improved barley variety that has been developed specifically for this region. Through contact with extension agents, however, farmers have access to general information that is relevant to management of barley production. Again, the hypothesized effect is ambiguous in terms of direction of sign. Larger areas cultivated by the farmer and the fragmentation of landholdings are expected to be positively associated with diversity. Altitude and rainfall are thought to be associated with increased number of varieties growing in a given area. Barley is a cool season crop but when temperature is low, severe damage can occur by frosts and, when high damage is commonly associated with water stress. Both stresses are assumed to reduce the number of varieties grown by a community.

\subsection{Statistical Analysis}

\section{3.1 Diversity Index}

The Shannon-Weaver Diversity Index $(\mathrm{H})$ has been commonly used in measuring the diversity of germplasm collections and diversity in ecological communities (e.g. Jain et al 1975). This index is used to estimate evenness of species by combining richness and relative abundance. The populations (pure lines) were subjected to further analysis to evaluate their inter- and intravarietal diversity. The Shannon-Weaver Diversity Index, H' has been used. It is defined as follows:

$\mathrm{H}^{\prime}=-\sum_{i}^{n}$ pilpi / ln $n$

Principal component analysis was performed, using Unscrambler software V. 9.6 (camo@camo.no), to evaluate the relation of characters between populations.

\subsubsection{Censored Regression}

Multivariate analysis has been applied to identify the social and economic factors that influence levels of diversity maintained on-farm. The statistical model is a multivariate regression analysis that recognizes the role of incomplete markets and transactions costs in farmer decision-making. It has been widely used to analyze farmer responses to policy changes in less-favored environments of developing economies. In recent years, the framework has been adapted in order 
to analyze the determinants of on-farm crop diversity by Van Dusen and Taylor (2005) and applied in a number of empirical contexts (e.g. Benin et al., 2004). The theoretical model leads to a multivariate regression in which the dependent variable, a diversity index, represents the outcome of economically optimal crop and variety choices made by the farm household.

The diversity indices that are used in this study have the property that they are censored from below. This censoring may occur from an underlying unobserved (latent) variable that determines the level of diversity at the farm level. An appropriate econometric model for such variable is a censored regression (Tobit) model. It accounts for censoring of the dependent variables, which occurs at the lower limit of each of the indices.

Suppose the latent dependent variable $y_{i}^{*}$ satisfies a classical linear model:

$$
y_{i}^{*}=x_{i} \beta+\varepsilon_{i}
$$

where, $\beta$ is a vector means and $\varepsilon_{i} \sim N\left(0, \sigma^{2}\right)$. An observed $y_{i}$ that is censored from below is given as:

$$
y_{i}=\left\{\begin{array}{l}
c \text { if } y_{i}^{*} \leq c \\
y_{i}^{*} \text { Otherwise }
\end{array}\right.
$$

where, $c$ is a given constant. The value of this constant depends on the specific diversity index under consideration.

In our analysis $y_{i}$ represents either the Margalef index of richness or the Shannon index of evenness, or Parker-Berger (dominance); $\quad x_{i}$ represents a vector of household characteristics for each household, farm and community factors; $\varepsilon_{i}$ is unobserved factors, and $\beta \mathrm{s}$ are the parameters to be estimated. We can consistently estimate $\beta$ using the maximum likelihood method. We used the Tobit command in STATA 8.1 to estimate the parameters of the model.

\subsubsection{MDPRR (Multidimensional Preference Analysis)}

Multidimensional Preference Analysis (MDPR) is a principal components analysis that projects both rows (landraces) and columns (various attributes) of a preference matrix onto a common 'preference space' (SAS, 2000). This method was used to investigate relationships among and within varieties as well as household differences for important traits. During the focused group discussion, major varieties currently growing in short and main seasons were recorded along 
with their most important characteristics. Farmers were asked to rate their preferences using 0-9 scale, where 0 means no preference and 9 high preference.

Table 3. Diversity index ( H') Estimates for Each Character by Population Level.

\begin{tabular}{|c|c|c|c|c|c|c|c|c|c|c|c|}
\hline Var/ACNO & \multicolumn{2}{|c|}{ DAFL } & DAM & $\mathrm{PH}$ & \multicolumn{2}{|c|}{ ROWNO } & \multicolumn{2}{|c|}{ SCLD } & \multicolumn{2}{|c|}{ SPKDEN } & SPKLEN \\
\hline Kinchso & \multicolumn{2}{|c|}{0.50} & 0.4 & 0.5 & \multicolumn{2}{|c|}{0.49} & 0.73 & & 0.50 & \multicolumn{2}{|c|}{0.69} \\
\hline Burguda & \multicolumn{2}{|c|}{0.70} & 0.44 & 0.5 & \multicolumn{2}{|c|}{0.65} & 0.72 & & 0.50 & \multicolumn{2}{|c|}{0.59} \\
\hline Gunaza & \multicolumn{2}{|c|}{0.60} & 0.56 & 0.5 & \multicolumn{2}{|c|}{0.56} & 0.81 & & 0.50 & \multicolumn{2}{|c|}{0.65} \\
\hline Shewa & \multicolumn{2}{|c|}{0.70} & 0.5 & 0.6 & \multicolumn{2}{|c|}{0.57} & 0.62 & & 0.50 & \multicolumn{2}{|c|}{0.70} \\
\hline Saesa & \multicolumn{2}{|c|}{0.55} & 0.68 & 0.4 & \multicolumn{2}{|c|}{0.61} & 0.69 & & 0.50 & \multicolumn{2}{|c|}{0.68} \\
\hline Zibna & \multicolumn{2}{|c|}{0.50} & 0.66 & 0.6 & \multicolumn{2}{|c|}{0.5} & 0.77 & & 0.50 & \multicolumn{2}{|c|}{0.62} \\
\hline Atsa & & & 0.54 & 0.55 & 0.7 & & 0.80 & & 0.50 & 0.7 & \\
\hline Himblil & & & 0.5 & 0.56 & 0.5 & & 0.86 & & 0.50 & 0.6 & \\
\hline Atona & & & 0.54 & 0.56 & 0.7 & & 0.62 & & 0.50 & 0.6 & \\
\hline Kintsbe & & & 0.63 & 0.63 & 0.7 & & 0.82 & & 0.50 & 0.5 & \\
\hline IBC1 & & & 0.53 & 0.62 & 0.5 & & 0.76 & & 0.50 & 0.7 & \\
\hline IBC2 & & & 0.78 & 0.48 & 0.6 & & 0.77 & & 0.60 & 0.6 & \\
\hline Total & & & 0.78 & 0.63 & 0.8 & & 0.84 & & 0.66 & 0.7 & \\
\hline Var/ACN & LMC & LMT & $\mathrm{KCO}$ & SEC & RAC & SSPK & ALC & GHB & GLC & ARUG & $\mathrm{H}^{\prime} \pm \mathrm{SE}$ \\
\hline Kinchso & 0.57 & 0.62 & 0.63 & 0.69 & 0.86 & 0.81 & 0.63 & 0.68 & 0.52 & 0.69 & $0.65 \pm 0.07$ \\
\hline Burguda & 0.50 & 0.69 & 0.63 & 0.43 & 0.89 & 0.70 & 0.63 & 0.50 & 0.4 & 0.65 & $0.54 \pm 0.06$ \\
\hline Gunaza & 0.50 & 0.81 & 0.63 & 0.43 & 0.67 & 0.50 & 0.63 & 0.50 & 0.4 & 0.56 & $0.58 \pm 0.06$ \\
\hline Shewa & 0.50 & 0.74 & 0.63 & 0.65 & 0.83 & 0.71 & 0.63 & 0.75 & 0.56 & 0.50 & $0.61 \pm 0.04$ \\
\hline Saesa & 0.50 & 0.62 & 0.63 & 0.43 & 0.92 & 0.50 & 0.63 & 0.65 & 0.47 & 0.62 & $0.58 \pm 0.04$ \\
\hline Zibna & 0.74 & 0.57 & 0.63 & 0.72 & 0.93 & 0.50 & 0.63 & 0.50 & 0.69 & 0.66 & $0.60 \pm 0.05$ \\
\hline Atsa & 0.57 & 0.65 & 0.63 & 0.68 & 0.93 & 0.73 & 0.63 & 0.50 & 0.73 & 0.75 & $0.67 \pm 0.05$ \\
\hline Himblil & 0.50 & 0.50 & 0.63 & 0.61 & 0.93 & 0.72 & 0.63 & 0.50 & 0.75 & 0.65 & $0.60 \pm 0.07$ \\
\hline Atona & 0.50 & 0.50 & 0.63 & 0.49 & 0.91 & 0.79 & 0.63 & 0.50 & 0.5 & 0.71 & $0.63 \pm 0.05$ \\
\hline Kintsbe & 0.50 & 0.50 & 0.63 & 0.43 & 0.93 & 0.74 & 0.63 & 0.59 & 0.4 & 0.72 & $0.65 \pm 0.05$ \\
\hline IBC1 & 0.50 & 0.73 & 0.77 & 0.43 & 0.75 & 0.67 & 0.63 & 0.63 & 0.56 & 0.66 & $0.68 \pm 0.04$ \\
\hline IBC2 & 0.74 & 0.64 & 0.81 & 0.56 & 0.94 & 0.86 & 0.63 & 0.82 & 0.62 & 0.71 & $0.74 \pm 0.03$ \\
\hline Total & 0.75 & 0.71 & 0.77 & 0.68 & 0.94 & 0.82 & 0.85 & 0.65 & 0.72 & 0.73 & $0.79 \pm 0.03$ \\
\hline
\end{tabular}

Var/ACN $=$ Varieties/Accession number, DAFL = Days to Flowering, DAM=Days to Maturity, $\mathrm{PH}=$ Plant Height, ROWNO= Row number, $\mathrm{SCLD}=$ Scald Resistance, $\mathrm{KCO}=$ Kernel Cover, lmc \& LMT $=$ Lema color \& Type, SEC=Seed Color, RAC=Rachila Hair Length, SSPK=Number of Seeds per Spike, $\mathrm{ALC}=$ Aleurone Color, $\mathrm{GHB}=$ Growth Habit, GLC $=$ Glume Color, and ARUG=Awn Roughness.

\section{RESULTS}

\subsection{Estimates of Phenotypic Diversity}

Polymorphism was revealed across all traits (Table. 3). The relative contribution of characters is varied. The regional pooled variation over traits ranges from $0.63-0.94$ with a mean value of 0.79. In this study, higher variation was found between and within varieties. Higher diversity is observed for length of rachila hair (0.94), row number (0.85), and scald resistance (0.84). At population level, the highest H' obtained from IBC2 (0.74) and lowest from Burguda (0.54). 


\subsection{Frequency and Distribution of Traits}

The frequency of distribution and amount of traits was found to be variable across varieties. Two rowed types were more common $(40.2 \%)$ than irregular-deficient $(37.7 \%)$ and six rowed $(22.2 \%)$. The highest occurrence of six row barley was recorded for Endamekhoni, and Ofla. Covered type barley was predominant (91.2\%) over naked types (8.8\%). Most of the populations were white $(71.5 \%)$ than black (15.5\%) purple $(0.4 \%)$ and red (12.6\%). Plant height is a highly polymorphic trait. Phenotypes of four plant height classes were noted in the population. 58.2\%, $21.3 \%, 13.4 \%$, and $7.1 \%$ were within the respective range of $\leq 45 \mathrm{~cm}, 44-66 \mathrm{~cm}, 67-87 \mathrm{~cm}$ and $\geq 88 \mathrm{~cm}$. Most of populations (79\%) were concentrated in two classes of less than $45 \mathrm{~cm}(58.2 \%)$ and within the range of 44-66 (21.3\%). Lemma type without a lemma teeth was the most prevalent trait reached (79.1\%) and lemma type with lemma teeth (18.8), and only $2.1 \%$ of the population were found with lemma type with no hair.

Three phenotypic classes of spike length were distributed across populations. $50.6 \%, 43.9 \%$ and $5.4 \%$ of the population were respectively grouped with $\leq 5 \mathrm{~cm}$ (short) $6-8 \mathrm{~cm}$ (medium) and 9-11 $\mathrm{cm}$ long. Seed number/spike was evenly distributed across defined classes. A respective frequency of $57.4 \%, 35.4 \%$, and $7.2 \%$ was recorded for seed number of less than $26 ; 27-48$; and 49. Most of the populations exhibited erect growth habit $(89.1 \%)$ compared to intermediate $(8.5 \%)$ and prostrate $(2.5 \%)$. Maturity was an evenly distributed trait and most of the populations represented the extra early to medium maturing group.

As shown in Figure 2a-b, a broad range of differences are noticed between varieties. The older gene-bank conserved samples were different from currently grown population. These population, labelled as IBC1 (for accno 219910) and IBC2 (for accno 223185), were discriminated by differences in spike length, lemma color/type, and alurone color than others (Figure 2a-b). Earliness, spike length and scald resistance are the main discriminating characters of these population. The highest significant correlations were found between days to maturity and flowering (0.78).

Currently growing/sampled varieties are associated with other characters. Varieties 'Shewa' and 'Himblil' are associated with scald resistance and awn roughness (Fig. 2b). The association of awn roughness was also expressed during the preference (MDPR) analysis, where 'Himblil', was distinguished by this trait. 'Saesa' is an extra early variety with shorter stature and spike length than others. The white lemma color and extra earliness of 'Saesa' are associated with utility 
preference and drought escape, respectively. 'Saesa' and 'Zibna' are two-rowed barley varieties known for their early maturity and susceptibility for scald. Despite their source of collection (Saesa from Eastern Zone and Zibna from Southern Zone), they are grouped in the same side of the PCA. On the other side of the PCA, some lines are displayed with medium maturity to moderately resistant to scald.
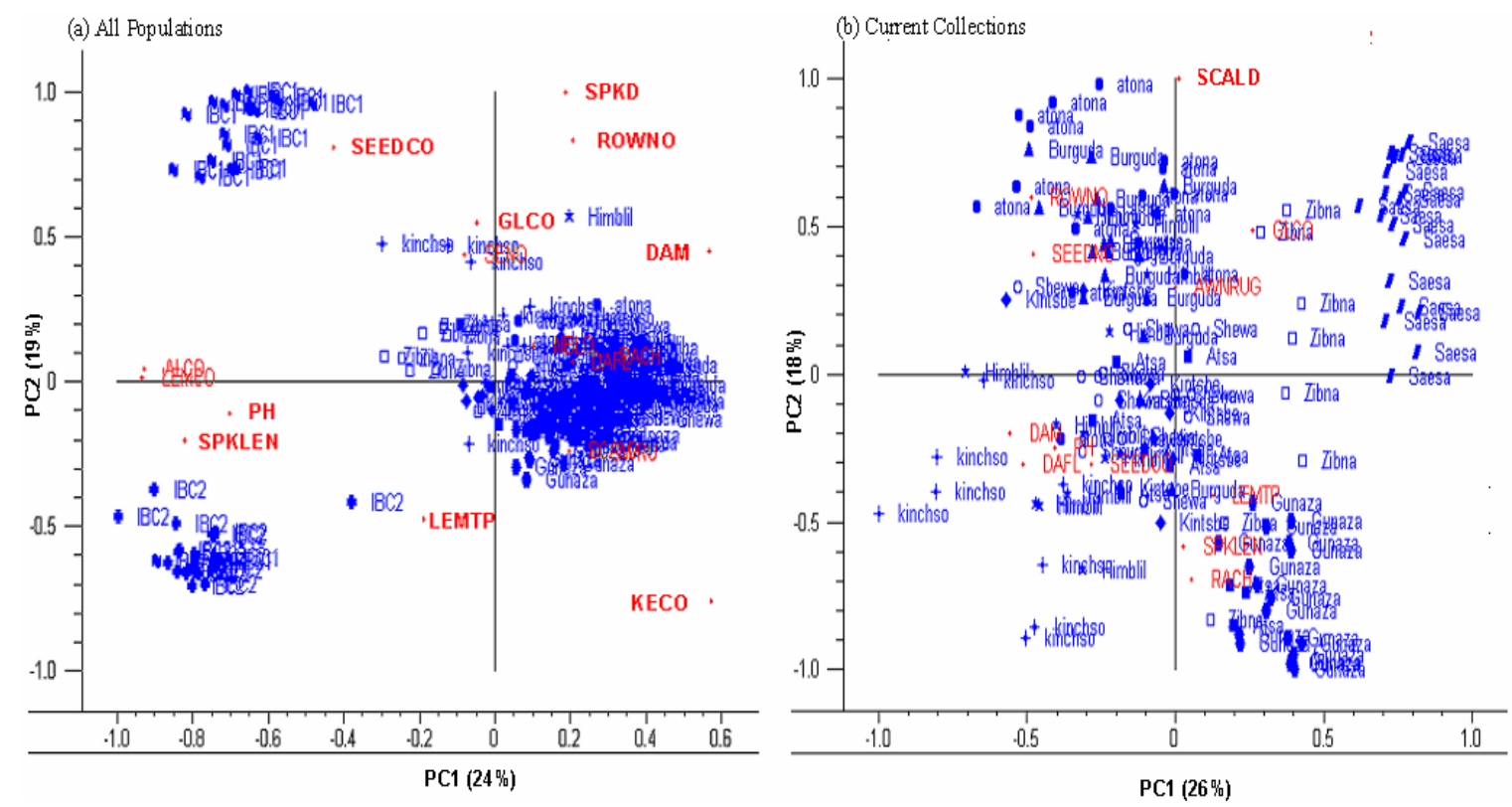

Figure 2. Biplot of current and earlier collections of barley varieties in Tigray [DAFL= Days to Flowering, DAM=Days to Maturity, $\mathrm{PH}=$ Plant Height, Seed/SPK= Number of Seeds per Spike. $\mathrm{SCALD}=$ Scald Resistance $\mathrm{LEMCO}=$ Lemma Color, $\mathrm{SEEDCO}=$ Seed Color, $\mathrm{KECO}=\mathrm{Kernel}$ Cover, LEMTP= Lemma Type, $\mathrm{RACH}=$ Rachila Hair Length, ALCO=Alurone Color, GRHB= Growth Habit, GLCO=Glume Color, and AWN RUG= Awn Roughness, (IBC1=ACCNO 219910, IBC2=2223185)].

Table 4. Summary of statistics of barley diversity on household farms in the highlands of Tigray region, Ethiopia.

\begin{tabular}{|lcclcc|}
\hline Diversity Index & N & Mean & Std. Deviation & Min & Max \\
Richness (Margalef index) & 249 & 0.1609 & 0.21262 & 0.00 & 0.96 \\
Evenness (Shannon-Weaver Index) & 249 & 0.3196 & 0.38384 & 0.00 & 1.61 \\
Inverse Dominance (Berger-Parker Index) & 249 & 1.3599 & 0.51983 & 1.00 & 5 \\
\hline
\end{tabular}


Table 5. Regression coefficients of household, farm and site variables in inter-varietal diversity of barley in Tigray.

\begin{tabular}{|c|c|c|c|}
\hline Variable & $\begin{array}{l}\text { Margalef } \\
\text { Coefficient }\end{array}$ & $\begin{array}{l}\text { Shannon } \\
\text { Coefficient }\end{array}$ & $\begin{array}{l}\text { Berger-parker } \\
\text { Coefficient }\end{array}$ \\
\hline \multicolumn{4}{|l|}{ Household characteristics } \\
\hline Age & $.022698 * *$ & $.0472391 * *$ & $.0720745^{* *}$ \\
\hline Age Squared & $-.0002138 * *$ & $-.0004581^{* *}$ & $-.0006919 * *$ \\
\hline Male headed & $.1267036^{*}$ & .1799909 & .1957306 \\
\hline Number of children in the household & $.029614^{*}$ & $.0533478^{*}$ & $.0796588^{*}$ \\
\hline Number of adults in the household & .0043233 & -.0060136 & -.0135633 \\
\hline Livestock ownership & $.0409019 * *$ & $.077068 * *$ & $.1111701^{* *}$ \\
\hline Education of hh head & -.0066457 & -.009078 & .0169208 \\
\hline Extension contact & $-.0375037 * *$ & $-.0821002 * *$ & $-.1137409 * *$ \\
\hline \multicolumn{4}{|l|}{ Farm characteristics } \\
\hline Fragmentation Index & $.1272958 * * *$ & $.2222815^{* * *}$ & $.3131929 * * *$ \\
\hline Farm size & $.3663155^{* * *}$ & $.7753678 * * *$ & $1.037034 * * *$ \\
\hline \multicolumn{4}{|l|}{ Site characteristics } \\
\hline Altitude & $.0008697 * * *$ & $.00159 * * *$ & $0020345 * * *$ \\
\hline Total rainfall & $.0003194 * *$ & $.0006413 * *$ & $.0009865^{* *}$ \\
\hline Maximum Temperature & .0368686 & .0477445 & .0221412 \\
\hline Minimum temp & $-.1467199 * * *$ & $-.2401835^{* *}$ & $-.2536648^{*}$ \\
\hline Constant & $-3.494105 * * *$ & $-6.256162 * * *$ & $-7.271685^{* * *}$ \\
\hline No of observations & 246 & 246 & 246 \\
\hline Psedu $\mathrm{R}^{2}$ & 0.7423 & 0.4700 & 0.3665 \\
\hline
\end{tabular}

\subsection{Econometric Analysis}

The varieties considered in this study are those populations recognized by farmers. The mean values for richness was 1.93, indicating that large number of households cultivate two varieties. Summary statistics for barley variety indices are shown in Table 4. Censored regression results of the determinants of barley diversity are presented in Table 5. Education had no significant effect across all indices. Both 'age' and its squared term were found to significantly influence diversity in quadratic form, with expected signs. Diversity increases at a decreasing rate as farmer's age. As hypothesized, households headed by men grow more diverse varieties. This 
might be associated with the skill or requirement for frequent ploughing and early planting of late-maturing barley varieties.

Households with large numbers of children were found to grow more evenly distributed varieties. The influence of this variable is uniform and significant across all indices. The econometric finding on large family size (high number of children) reflects the importance of the crop for large families as they have different preferences. It was also confirmed by the focus group discussions where one informant told the following story.

"Once upon a time there was a plant Sorghum; as it was growing, there came Barley. The Barley was much younger than the Sorghum, but it rushed to grow up and mature. When the Sorghum saw this, it asked the Barley to wait for it, so that they can mature together, but the Barley said it could not wait, as it had hungry mouths to feed at home. Thus, the Barley rushed and matured before the Sorghum."

No statistical association was found between number of adults and diversity indices. As expected, wealth in large livestock assets was found to be a significant and positive determinant across all indices. This variable is associated with the increased requirement for fodder and need for oxen. Land preparation for cereal crops is more labor-intensive than preparation for pulses; for example, it requires more draught power. All cultivation is carried out by oxen, except for some small and very difficult areas in the highlands, where hoe cultivation is practiced. The number of times a field has to be ploughed depends on the condition of the soil as well as the crops to be sown.

There appears negative and significant relation of extension with all diversity indices but with different size. This might be associated with the current agricultural policy, based on agricultural led industrialization, overlooks the role of local varieties and give attention to cash based farming of legumes and cereals other than barley. Tin et al. (2001) described the effect of genetic change due to agricultural intensification in Vietnam. Similarly changes in genetic diversity and cropping system may occur in Tigray. The effects of farm sizes and land fragmentation are positive, statistically strong and large in magnitude, indicating the heterogeneity in soils and growing conditions (Abay et al., 2008). With increased altitude, richness, evenness and dominance were increased. This is in agreement with the initial assumption on adaptation leading to a higher number of barley varieties in the highland barley-growing areas, which are known for their extended growth period and relatively good distribution of rainfall. Increased number of 
varieties, more evenly distributed and dominance is found with increased rainfall. A negative and significant association of minimum temperature is found as predicted across all indices but no statistical relation was found with maximum temperature.

In general, the findings suggest that in this marginal environment, physical characteristics of the farm and production technology (livestock, land), and agro climatic features of the site and household characteristics have a greater impact on variation in barley diversity levels across household farms than household characteristics as was found by Benin et al. (2004)

Altitude, land fragmentation, squared age, farm size, total rainfall and minimum temperature were significant and positively associated with all diversity indices. Extension was the only significant variable associated negatively.

\subsubsection{Contribution of Farmers' Trait preferences to varietal diversity}

Information on diversity of the uses of barley varieties sheds more light on the variety choices of farmers. In this case, at Bolenta village (Enda-Mokeni District), we found farmers use the name 'Himblil' for both the local and the farmer's developed variety from 'Himblil' (Abay et al., 2007 submitted). For the purpose of this analysis, the varieties were marked as 'HimbLoc and 'Himbkah'. The most important traits found to explain the variation in PC1, were straw yield, and utility related traits like 'geat' (porridge) 'kolo' (crispy roasted grain) and 'kitta' (flat bread) with grain yield, plant height, 'injera' (pancake), and number of seeds/spike. In PC2 earliness, drought resistance and beer quality 'siwa' were explained (Fig. 3).

'Himbkah' was mainly preferred for its good yield, stature, seed size and better 'injera' (pan cake). Although, it was not preferred for straw palatability and most utility related traits, it has brought an improvement over the original variety over those traits. This variety can be easily identified by its stiff straw and chaffy spikes (Fig. 3). PC2 differentiated early maturing with late maturing varieties. For example, Saesa, (two rowed extra early variety) is located opposite to Demhay (six rowed-late maturing). Both of them might be important for studying earliness and beer (malt) quality. The results indicate the contribution of multiple preferences of household members for intravarietal diversity, in addition to natural selection. Preference differences observed within the variety that farmers referred to as Himblil can be considered as largely the role of farmers' selection. 


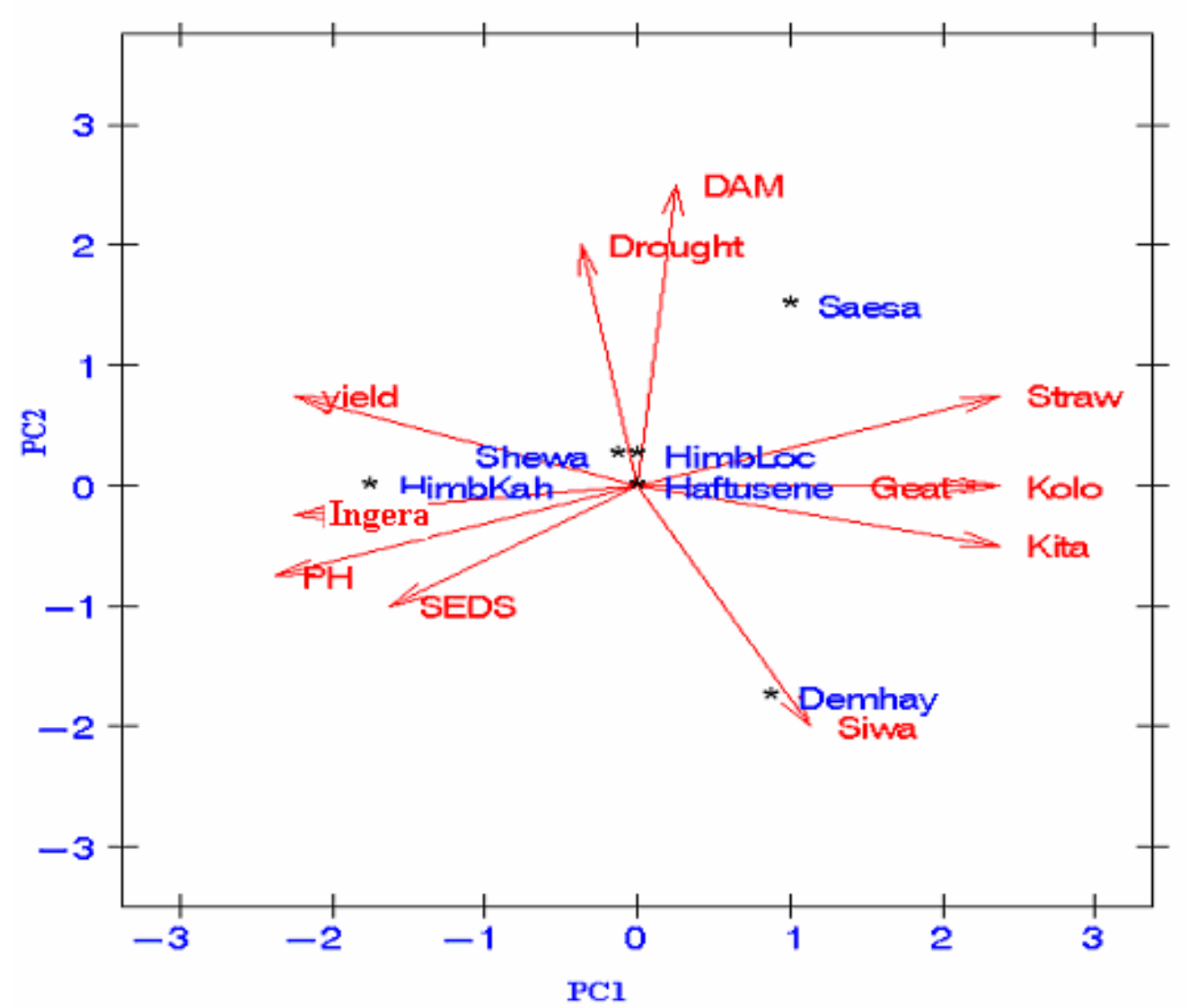

Figure 3. biplot of farmers varieties by use value and agro-morphological characters [PH=Plant height, drought $=$ drought resistance, Yield and Straw (grain and straw yield), Injera, Geat and Kita $=$ all local pan cakes prepared in different forms, Kolo= snack as roasted grain and Siwa $=$ local beer].

\subsubsection{Discussion and Implications for development and research}

In the marginal environments of Tigray, distinctive genetic barley materials have been selected and enhanced by local farmers. There are several reasons why local varieties have proved to be sustainable under the conditions in Tigray. We found diversity associated with farmers' preferences for household consumption, variation in climatic and geographic variables. Teshome et al. (1999) showed that sorghum landrace diversity in Ethiopia was significantly related to a number of farmer selection criteria. The highest diversity index (0.79) is related to earlier findings. More diversity is found in areas known with variation over time and space (Teshome et al., 1997). Demissie and Bjørnstad $(1996,1997)$ study the influence of agro ecological variation on selection in barleys in Ethiopia. Bechere et al. (1996) found more diversity for durum wheat 
samples collected from Tigray. Gari (2004), pointed out dry land areas have often been stigmatized as not being interesting for crop production, while in actual fact they host a unique biodiversity that has co-evolved with changing agro-ecological conditions and indigenous practices and innovation. The differences between currently grown and earlier collected accessions need further analysis.

The high frequency maintained by the erect growth habit might be related with its adaptation to poor edaphic conditions, and barley is mostly grown in areas that can not be allocated for other cereals. Grain color is the most important preferred criteria associated with consumption preference. Similar results were reported by Demissie and Bjørnstad (1996). As described by Kebebew et al. (2001), it might be related environmental adaptation and farmers' selection. The highest diversity for scald is observed for variety 'Himblil', a farmer developed variety (Abay et al., 2008). The high diversity (0.84) for scald is similar to the earlier study on Ethiopian barleys (Van Leur and Hailu 2003, Fekadu and Parlevliet, 1997; Demissie and Bjørnstad 1996, 1997) in which late-maturing and six-rowed barley varieties are associated with high-altitude and high rainfall areas. Di Falco et al. (2006) explained the importance of variety diversification for areas like Tigray, as an important farm strategy for managing production risk with implications for farmer welfare. These authors found a positive effect of diversity on productivity of barley.

Most of our results are consistent to the results of related studies made by Benin et al. (2004) and Gebremedhin et al. (2006) for cereals. Physical characteristics of the farm (land fragmentation index, farm size), agro climatic features of the site (altitude, rainfall temperature) and household characteristics (only number of children) had a significant and positive impact on diversity and area allocation of barley. With the exception of minimum temperature, we found a significant positive effect on richness, evenness and dominance of barley varieties. The negative association with minimum temperature might be associated with its frost sensitivity, although the trait does occur. This is in agreement to phenotypic diversity index reported in this study $\left(H^{\prime}=0.79\right)$ and earlier studies on Ethiopian barley (Demissie and Bjørnstad, 1996) and wheat (Bechere et al., 1996). Fekadu and Parlevliet (1997) and Demissie and Bjørnstad (1997) also found high diversity in areas of high altitude and cooler temperature.

The negative influence of extension contact with barley richness needs special attention of promoting local varieties known for their increased productivity. As it was noted by Gari (2004), farmers can be motivated to maintain crop diversity if extension and market policy encourages 
commercial products made of local crops. According to Assefa and Adugna (2002), in other areas of Ethiopia, oxen ownership, availability of fertilizers and availability of labor are major determining factors. In our case, most of female-headed households have no skill to plough and no oxen. Policies made to encourage oxen ownership are not found to be supportive to female household heads. Other studies of this region have shown that the number of oxen owned by a farmer strongly influences both the area cultivated and the cropping patterns (Abay et al., 2001). Under these conditions female headed households may prefer a less demanding variety (in terms of land preparation). Similarly Mamusha et al. (2000) found that women in Tigray had difficulties in ploughing their land. They have to wait to have their land ploughed by male relative or a neighbour. This puts the single woman at a double disadvantage. Her fields are planted later, and each day's delay in sowing reduces the final yield and choices to plant. Then, she has to plant a variety which can suit with her ploughing time. Farmers' innovation on varietial selection and their multiple objectives towards the plants differential response and their diverse utility preferences has been confirmed through this study. Similar findings were reported by Tsehaye et al. (2005) for finger millet in Tigray.

Collectively, the results from diversity index and MDPR analysis confirm the presence of phenotypic diversity within and between varieties. The determinants of this variability are found to be associated with household, farm and policy environments. The study has some important implications. First, we have documented the existing diversity of farmer-named varieties, which can serve as an entry point for decentralized participatory breeding. Second, the socio-economic determinants of barley diversity are analyzed, highlighting some policy directions to support the local resource development. This study implies as a potential to exploit the genetic differences under the conditions and additional advantage of making use of farmers' knowledge of the crop.

\section{REFERENCES}

Fetien Abay, Waters-Bayer, A \& Bjornstand A. 2008. Farmers' Seed Management and Innovation in Varietal Selection: Implications for Barley Breeding in Tigray, Northern Ethiopia. Ambio, 37(4):312-320

Abay, F., Mamusha, L., Waters-Bayer, A \& O'Flynn, P. 2001. A challenge and an opportunity: innovation by women in Tigray. In:Reij $\mathrm{C}$ and Waters-Bayer, A (eds.): Farmer 
Innovation in Africa: A Source of Inspiration for Agricultural Development. Earthscan, 155-167 pp.

Almekinders, C.J.M., Louwaars, N \& de Bruijn, G. 1994. Local seed systems and their importance for an improved seed supply in developing countries. Euphytica, 78: 207-16.

Assefa, B \& Adugna, T. 2002. Eradicating rural poverty and food insecurity in Ethiopia: the quest for sustainable institutions and technologies. Paper presented at the Ethio-Forum 2000 International Conference on Community-Driven Poverty Eradication and Restorative Development in Ethiopia, 15-19 January 2002, Addis Ababa, Ethiopia.

Bellon, M.R \& Taylor, J.E. 1993. "Folk" soil taxonomy and the partial adoption of new seed varieties. Economic Development and Cultural changes, 41(4): 763-786.

Benin, S., Smale, M., Pender, J., Gebremedhin, B \& Ehui, S. 2004. The economic determinants of cereal crop diversity on farms in the Ethiopian highlands. Agricultural Economics, 31: 197-208.

Berger, W.H \& Parker, F.L. 1970. Diversity of Planktonic Foraminifera in deep sea sediments. Science, 168: 1345-1347.

Bechere, E., Belay, G., Mitiku, D \& Merker, A. 1996. Phenotypic diversity of tetraploid wheat landraces from northern and norh central regions of Ethiopia. Hereditas, 124: 165-172.

Birhanu, B., Fekadu, A \& Berhane, L. 2005. Food barley in Ethiopia. In: S. Grando and M. H. Gomez (Eds), Food barley: importance, uses and local knowledge. Proceedings of the International Workshop on Food Barley Improvement, 14-17 January 2002, Hammamet, Tunisia. Aleppo: ICARDA. 53-81 pp.

BoARD (Bureau of Agriculture and Rural Development). 2005. Annual evaluation report of cereal production in Tigray, Mekele: BoARD.

Brush, S.B \& Meng, E. 1998. Farmers' valuation and conservation of crop genetic resource. Genetic Resources and Crop Evolution, 45: 139-150.

Ceccarelli, S. 1996. Positive interpretation of genotype by environment interaction in relation to sustainability and biodiversity, In: M. Cooper and G.L. Hammers (Eds.) Plant adaptation and crop improvement. CAB Int., Wallingford. UK. ICRISAT, Andra Paradesh, India, IRRI, Manila Philippines, 467-486 pp. 
Demissie, A \& Bjørnstad, Å. 1996. Phenotypic diversity of Ethiopian barley in relation to geographical regions, altitudinal range, and agro-ecological zone as an aid to germplasm collection and conservation strategy. Hereditas, 124: 17-29.

Demissie, A \& Bjørnstad, Å. 1997. geographical, altitude and agro ecological differentiation of isozyme and hordein genotypes of landrace barleys from Ethiopia. Genet. Resources Crop Evol., 44:43-55.

Di Falco, S., Chavas, J \& Smale, M. 2006. Farmer management of production risk on degraded Lands: the Role of Wheat Genetic Diversity in Tigray Region, Ethiopia IFPRI, Discussion Paper.

Ellis, F. 1998. Survey article: household strategies and rural Livelihood Diversification'. The Journal of Development Studies, 35(1):1-38.

Fekadu, A \& Parlevliet, J.E. 1997. Variation between and within Ethiopian barley landraces. Euphytica, 94: 183-189.

Gari, J.A. 2004. Plant diversity, sustainable rural livelihoods and the HIV/AIDS crisis. UNDP/FAO South East Asia HIV and Development Programme.

Gebremedhin, B., Smale, M., Pender, J \& Ehui, S. 2006. Determinants of cereal diversity in villages of Northern Ethiopia. Pp. 177-192. In: M. Smale (Ed.) Valuing Crop Biodiversity: On Farm Genetic Resources and Economic Change. CAB International.

G'orny, A.G. 2001. Variation in utilization efficiency and tolerance to reduced water and nitrogen supply among wild and cultivated barleys. Eupytica, 117: 59-66.

Grando, S., R. von Bothmer \& S. Ceccarelli. 2001. Genetic diversity of barley: Use of locally adapted germplasm to enhance yield and yield stability of barley in dry areas. In: Cooper, H. D., C. Spillane and T. Hodgkin (Eds.).Broadening the genetic base of crop production. CABI, New York/FAO, Rome/IPGRI, Rome, 351-372 pp.

Haugerud, A \& Collinson. M.P. 1990. Plants, genes, and people: Improving the relevance of plant breeding in Africa. Experimental Agriculture, 26: 341-362.

IPGRI. 1994. Descriptors for Barley (Hordeum vulgare L.). International Plant Genetic Resources Institute, Rome, Italy

Jain, S.K., Qualset, C.O., Bhatt, G.M \& Wu, K.K. 1975. Geographical patterns of phenotypic diversity in a world collection of durum wheat. Crop Sci., 15: 700-704. 
Kebebew, F., Tsehaye, Y \& McNeilly, T. 2001. Morphological and farmers' cognitive diversity of barley (Hordeum vulgare L. [Poaceae]) at Bale and North Shewa of Ethiopia. Genetic Resources and Crop Evolution.

Maaza, W \& Lakech, T. 1996. Barley utilization in Ethiopia. In: G. Hailu and J. van Leur (Eds.), Barley Research in Ethiopia: Past Work and Future prospects. Proceedings of the First Barley Research Review Workshop, 16-19 October 1993, Addis Ababa: IAR/ICARDA. Addis Ababa, Ethiopia, 21-31 pp.

Magurran, A.E. 2004. Measuring Biological Diversity. Malden: Blackwell.

Mamusha, L., Abay, F \& WATERs-BAYER, A. 2000. Women challenge cultural norms in Tigray. In: ILEIA Newsletter, 16 (2):40.

Munck, L.K., Karlson, R \& Hagberg, A. 1971. Selection and characterization of High protein, High-lysine variety from the world barley collection. In: Barley Genetics II. Proceeding, $2^{\text {nd }}$ Int. Barle Genet. Symp., Pullman, WA, USA, 544-558 pp.

Qualset, C. O. 1975. Sampling germplasm in a center of diversity: an example of disease resistance in Ethiopian barley. In: O.H. Frankel and J.G. Hawkes (Eds.), Crop genetic resources for today and tomorrow, Cambridge University Press, 81-96 pp.

Reinheimer, J.L., Barr, A.R \& Eglinton, J.K. 2004. QTL mapping of chromosomal regions conferring reproductive frost tolerance in barley (Hordeum vulgare L.). Theoretical and Applied Genetics Springer Berlin / Heidelberg, 1267-1274 pp.

SAS. 2000. SAS user's guide, Released $9^{\text {th }}$ edition. Cary, North Carolina: SAS Institute Inc.

Teshome, A., Baum, B.R., Fahrig, L., Torrance, J.K., Arnasen, T.J \& Lambert, J.H. 1997. Sorghum [Sorghum bicolor (L.) Moench] landrace variation and classification in north Shewa and south Welo, Ethiopia. Euphytica, 97: 255-263.

Teshome, A., Fahrig, L., Torrance, J.K., Lambert, J.H., Arnasen, T.J \& Baum, B.R. 1999. Maintenance of sorghum (Sorghum bicolor) landrace diversity by farmers' selection in Ethiopia. Econ. Bot., 53: 79-88.

Tin, H.Q., Berg, T \& Bjørnstad, Å. 2001. Diversity and adaptation in rice varieties under static (ex situ) and dynamic (in situ) management. A case study in the Mekong Delta, Vietnam Euphytica, 122: 491-502. 
Tsehaye, Y., Berg, T., Bayush, T \& Tesema, T. 2005. Farmers' management of finger millet (Eleusine coracana L.) diversity in Tigray, Ethiopia, and implications for on-farm conservation. Biodiversity and Conservation Springer Netherlands.

van Leur, J.A.G \& Hailu, G. 2003. Diversity between some Ethiopian farmers' varieties of barley and within these varieties among seed sources. Genetic Resources and Crop Evolution, 50: 351-357.

Van Dusen, E \& Taylor, J. E. 2005. Missing markets and crop diversity: evidence from Mexico. Environment and Development Economics, 10 (4): 513-531. 